\title{
TÜRKİYE İÇİN İTHALAT TALEP FONKSİYONU TAHMİNİ (1970-2016)
}

\section{Can APAYDIN*, Aslı Seda KURT**}

öz

Bu çalışmanın amacı Türkiye için ithalat talep fonksiyonunu ARDL sınır testi yöntemiyle ve esneklikler yardımıyla tahmin emektir. Çalışmada kullanılan zaman serileri OECD ve FRED veri tabanlarından edinilen ithalat, reel gayrisafi yurtiçi hasıla ve reel efektif döviz kurudur. Bu seriler 1970-2016 arasını kapsayan yıllık serilerdir. Çalışmanın sonunda ithalat, reel gayrisafi yurtiçi hasıla ve reel efektif döviz kuru arasında eş bütünleşme saptanmıştır. Ayrıca ithalatın gelir esnekliği beklenildiği gibi pozitif $(0,872)$ ve reel döviz kuru esnekliği de negatif $(-0,629)$ hesaplanmıştır.

Anahtar Sözcükler: ARDL Sınır Testi, Eş Bütünleşme, İthalat Talep Fonksiyonu

\section{ESTIMATION OF IMPORT DEMAND FUNCTION FOR TURKEY (1970-2016) \\ ABSTRACT}

The aim of this study is to estimate import demand function for Turkey with ARDL bound testing method and by means of elasticities. Time series that are used in this study are import, gross domestic product and real effective exchange rate, which are obtained from database of the OECD and FRED. These series are annual that includes between 1970 and 2016. At the end of the study, cointegration have been determined among import, gross domestic product and real effective exchange rate. Besides, as it is expected, income elasticity of import have been calculated as positive $(0.872)$ and real exchange rate elasticity of import as negative (-0.629).

Keywords: ARDL Bound Test, Cointegration, Import Demand Function

* Ondokuz Mayıs Üniversitesi, İktisadi ve İdari Bilimler Fakültesi, İktisat Bölümü, Samsun, E-posta: can.apaydin@omu.edu.tr,

https://orcid.org/000-0003-0341-2548

** Dokuz Eylül Üniversitesi, İktisadi ve İdari Bilimler Fakültesi, İktisat Bölümü, İzmir, E-posta: asliseda.kurt@deu.edu.tr,

(iD) https://orcid.org/0000-0003-0356-7443 


\section{GİRIŞ}

Ülkeler, yurt içinde üretilmeyen veya üretim miktarı yurt içi talebi karşılamayan mallar için dış ticaret yoluyla iki yönlü bir mal ve hizmet aktarım mekanizması oluşturmaktadırlar. Bunlar, malların ve hizmetlerin diğer ülkelerden satın alınması (ithalat) ile malların ve hizmetlerin yurt dışına satılmasıdır (ihracat). Bir ülkenin ithalat ve inracat büyüklüğünü açıklamaya yardımcı olan parametreler fonksiyonel ilişki çerçevesinde tanımlanmaktadır. Bu fonksiyonel ilişki ve fonksiyon parametreleri zaman içerisinde geliştirilerek ortaya konmaktadır.

Ülkeler arasındaki rekabetin ölçüsü olarak kullanılan dış ticaret hacmi ülkelerin mal ve hizmet ithalat ve ihracat toplamlarından oluşmakta ve aynı zamanda önemli bir gelişmişlik göstergesi olmaktadır. Günümüzde küresel düzeyde rekabet avantajına sahip olmanın şartı ticaret hacmini geniş tutabilmekten geçmektedir. Zaman içerisinde küreselleşmeyle beraber gelen entegrasyon, Avrupa Birliği, Dünya Ticaret Örgütü, Kuzey Amerika Serbest Ticaret Bölgesi gibi bazı ticareti düzenleyici kuruluşların kurulması ve teknolojik faktörlerin devreye girmesiyle birlikte dış ticaret çok farklı bir boyut kazanmakta ve gelişmiş ülkelerin lehine doğru değişmektedir. Bu süreçte unutulmaması gereken bir başka nokta; malların ve hizmetlerin ülkeler arasında serbest dolaşımının yanı sıra finansal sermayenin de serbest dolaşımının önemli bir boyuta ulaşmış olmasıdır. Ancak bu dolaşım, dış ticaretin reel sektör cephesinde ele alınmamakta, dolayısıyla bu çalışmanın kapsamı dışında kalmaktadır. Bununla birlikte ihracat da bu çalışmanın kapsamı dışındadır.

\section{TEORİK VE AMPİRİK ARKAPLAN}

Bir ülkenin ithalat talebini etkileyen başlıca faktörler ulusal geliri ve ithal malların göreli fiyatlarıdır. Ulusal gelirdeki artışlar, -ceteris paribusithalatı artırmaktadır. Ulusal paranın yabancı paralar karşısında reel olarak değer kazanması da yine ithalatı artıracaktır. Çünkü ulusal paranın değerinde meydana gelen göreli artış, mal fiyatları sabitken nispi olarak ithal malların ucuzlamasına yol açmaktadır. Bunların dışında son zamanlarda oldukça tartışılan dış ticaret politikaları olan tarifeler ve tarife dışı engeller ile de ithalat dışsal olarak etkilenebilmektedir. Ancak günümüzde uluslararası kuruluşların serbest ticaret lehine uygulamaları bu araçların kullanımını sınırlandırmaktadır. Ayrıca şüphesiz ki ulaştırma masrafları ve zaman maliyeti nedeniyle coğrafi koşullar, kültür, tüketicilerin zevk ve tercihleri gibi nedenler de ithalatı etkilemektedir. Örneğin, geleneksel tüketim kalıplarını sürdürmekte ısrarlı olan ülkelerin 


\section{Can APAYDIN, Aslı Seda KURT}

ithalat talebi düşük olabilmektedir. Yine, gösteriş tüketimi ve/veya züppe etkisi gibi nedenlerle de dış mallara talep yüksek olabilmektedir. Tüm bu belirleyenler içinde ulusal gelir ve döviz kuru değişkenleri, ithalat talep fonksiyonunda gelir ve nispi fiyat etkilerinin gözlenebilmesi açısından temel faktörler olma özelliklerini korumaktadırlar.

Zaman serisi literatüründe ithalatı etkileyen değişkenler üzerine birçok çalışma yer almaktadır. Yavuz ve Güriş (2006), Vergil ve Erdoğan (2009), Bahmani-Oskooee ve Kara (2005) Türkiye için yapılan ve ARDL yönteminin kullanıı eş bütünleşmenin saptandığı çalışmalardır. Narayan ve Narayan (2003), Fosu ve Joseph (2008), Onwuka ve Zoral (2009), Hye ve Mashkoor (2010), Serge Constant ve Yue (2010), Englama, Oputa, Sanni, Yakub, Adesenya, ve Sani (2013), Gözgör (2014) ve Mugableh (2017) ise Türkiye dışındaki ülkeler için yapılan ve ARDL yönteminin kullanılıp eş bütünleşmenin saptandığı çalışmalardır.

Kotan ve Saygılı (1999), Aydın, Çıplak ve Yücel (2004), Bayraktutan ve Bıdırdı (2010) Türkiye için yapılan ve Engle-Granger yöntemi kullanılarak eş bütünleşmenin gözlendiği çalışmalardır. Hamori ve Matsubayashi (2001), Shareef ve Tran (2007), Wijeweera, Nur ve Dollery (2008) ise Türkiye dışındaki ülkeler için yapılan ve Engle-Granger yöntemi kullanılarak Hamori ve Matsubayashi (2001) hariç eş bütünleşmenin gözlendiği çalışmalardır.

Gül ve Ekinci (2006), Kalyoncu (2006), Togan ve Berument (2007), Altıntaş ve Türker (2014) Türkiye üzerine yapılmış ve Johansen testinin kullanıldığı çalışmalardır. Bahmani-Oskooee (1998), Bahmani-Oskooee ve Niroomand (1998), Fullerton ve Sprinkle (2005), Dutta ve Ahmed (2004), Rehman (2007) Türkiye dışındaki ülkeler üzerine yapılmış ve Johansen testinin kullanıldığı çalışmalardır. Her iki grupta da eş bütünleşme bulunmuştur.

Türkiye üzerine yapılan; Kutlar ve Şimşek (2003), Utkulu ve Seymen (2004), Yamak ve Korkmaz (2005) VAR analizi, Bayramoğlu ve Şükrüoğlu (2016) Maki eş bütünleşme testi sonucunda eş bütünleşme saptanmıştır.

\section{MODEL}

Çalışmada Türkiye'nin ithalat eğilimini çözümleyebilmek amacıyla ithalat fonksiyonları modellenmiştir. İthalat, gelir ve göreli fiyatlar arasındaki ilişkilerin gösterildiği fonksiyonun kapalı formu aşağıdaki gibidir:

$$
M=f(Y, R)
$$




\section{Türkiye İçin İthalat Talep Fonksiyonu Tahmini (1970-2016)}

İthalat fonksiyonu değişkenleri sırasıyla $M$, ithalat harcamasını temsil eden ithalatın parasal değerini, $Y$; ülke gelirini temsil eden sabit fiyatlarla gayri safi yurtiçi hasılayı, $R$; göreli fiyatları temsil eden reel efektif döviz kurunu göstermektedir. İthalat, gelir ve döviz kuru arasındaki ilişkilerin gösterildiği fonksiyonun açık ve logaritmik hali aşağıdaki gibidir:

$L M t=a 0+a 1 L Y t+a 2 L R t+\varepsilon t$

Çalışmaya ilişkin seriler OECD ve FRED veri tabanlarından alınmıştır. Bu seriler 1970 ile 2016 yıllarını kapsayan yıllık serilerdir. M ve $Y$ değişkenleri dolar cinsinden, $R$ ise 2010 baz yıllı endeks cinsinde birimlerdir. Buna ek olarak modeldeki değişkenlerin yüzde değişim cinsinden etkilerine bakmak için değişkenlerin doğal logaritması alınmıştır. Dolayısıyla değişkenlerin başındaki "L" harfi, değişkenlerin logaritmik olduğunu ifade etmektedir. Çalışmadaki tüm analiz E-views 9 ekonometri paket programıyla yapılmıştır.

\section{YÖNTEM}

Çalışmada, ülke gelirinin ve reel efektif döviz kurunun, ithalat harcamasıyla olan ilişkisi ARDL sınır testi yöntemiyle sınanmıştır. Bu yöntem, değişkenler arasında eş bütünleşmenin var olup olmadığının ortaya konmasına yardımcı olmaktadır. Eş bütünleşme literatüründe oldukça sık kullanılan bu yöntemin temelini, Engle ve Granger'ın hata terimine dayanan eş bütünleşme testi oluşturmaktadır. Söz konusu test için değişkenlerin aynı dereceden durağan olması gerekmektedir (Engle ve Granger, 1987). Ekonometri yöntem setinde bulunan bir diğer eş bütünleşme testi de Johansen ve Johansen ve Juselius'un geliştirdikleri ve en yüksek olabilirlik yöntemine dayanan eş bütünleşme testidir (Johansen, 1988). Engle ve Granger'ın eş bütünleşme yöntemi gibi Johansen ve Johansen ve Juselius'un geliştirdikleri yöntem de aynı derecede durağan olan değişkenler arasındaki eş bütünleşmenin varlığını sınamaktadır (Johansen ve Juselius, 1990). Dolayısıyla farklı derecede durağan değişkenler arasında eş bütünleşmenin varlığının sınanmasını olanaklı kılan ARDL yöntemi bu alandaki eksikliği ortadan kaldırmaktadır.

ARDL sınır testi yaklaşımı Pesaran, Shin ve Smith tarafından geliştirilmiştir. Bu yaklaşımın en önemli avantajı daha önce vurgulandığı gibi değişkenlerin durağanlık dereceleri farklı olsa bile (ikinci farkta durağan değişkenler hariç) eş bütünleşmenin araştırımasını olanaklı kılmasıdır. Ayrıca kısıtsız hata düzeltme modeli sayesinde Engle ve Granger'a göre daha güvenilir sonuçlar vermektedir. Bunun yanı sıra 


\section{Can APAYDIN, Aslı Seda KURT}

gözlem sayısı az olsa bile tutarlı sonuçlar vermektedir (Pesaran, Shin ve Smith, 2001).

\section{BULGULAR}

\section{ADF Birim Kök Testi}

Dickey - Fuller testi, değişkenlerin yalnızca birinci gecikmelerinde birim köke sahip olup olmadıklarını incelemektedir. Bu test Dickey ve Fuller tarafından geliştirilmiştir (Dickey ve Fuller, 1979). Genişletilmiş Dickey Fuller (ADF), Dickey - Fuller (DF) testine göre daha fazla gecikmeli değişkene sahiptir (Dickey ve Fuller, 1981).

Dickey - Fuller (DF) ilgilenilen değişkenin AR(1) biçimine dayanmaktadır:

$$
y=\lambda y t-1+u t
$$

Yukarıdaki denklemde eşitliğin her iki tarafından yt-1 değişkeni çıkarıldığında:

$$
\begin{aligned}
& y-y t-1=\lambda y t-1-y t-1+u t \\
& \Delta y=(\lambda-1) y t-1+u t \\
& \Delta y=\delta y t-1+u t
\end{aligned}
$$

Dickey ve Fuller yukarıdaki elde edilen nihai model ile birlikte sadece sabit terim ve sabit terim ile trend içeren iki model daha geliştirmiş̧ir:

$$
\begin{aligned}
& \Delta y=\mu+\delta y t-1+u t \\
& \Delta y=\mu+\gamma t+\delta y t-1+u t
\end{aligned}
$$

Elde edilen modellerin hata terimlerinde otokorelasyon sorunu ortaya çıkabilmektedir. Çünkü değişkenin yalnızca birinci gecikmesi modelde yer almaktadır. Böylece DF testi asimptotik olarak geçerliliğini yitirir. Dolayısıyla asimptotik geçerliliği sağlamak adına hata terimlerinin belli bir derece özbağlanımlılık (autoregressive) süreci izlediği varsayımında ADF testi geliştirilmiştir. ADF testinin asimptotik olarak geçerliliği Said ve Dickey (1984) ile Philips ve Peron (1988) tarafından ispatlanmıştır.

DF testine $p$ tane gecikme eklendiğinde aşağıdaki denklemlere ulaşılmaktadır:

$$
\begin{aligned}
& \Delta y=\delta y t-1+\sum_{\mathrm{j}=1}^{\mathrm{p}} \alpha_{\mathrm{j}} \Delta \mathrm{y}_{\mathrm{t}-\mathrm{j}}+e t \\
& \Delta y=\mu+\delta y t-1+\sum_{\mathrm{j}=1}^{\mathrm{p}} \alpha_{\mathrm{j}} \Delta \mathrm{y}_{\mathrm{t}-\mathrm{j}}+e t
\end{aligned}
$$




$$
\Delta y=\mu+y t+\delta y t-1+\sum_{\mathrm{j}=1}^{\mathrm{p}} \alpha_{\mathrm{j}} \Delta \mathrm{y}_{\mathrm{t}-\mathrm{j}}+e t
$$

Tablo 1'deki ADF birim kök testi sonuçlarına göre maksimum gecikme sayısı 10 iken sadece sabit ve sabit ile trend içeren durumlarda LY ve LM düzeyde, $L R$ ise birinci farkta durağandır. ARDL sınır testi yaklaşımı serilerin düzeyde ve/veya birinci farkta durağan çıkmasına karşı duyarlı değildir.

Tablo 1: ADF Birim Kök Testi Sonuçları

\begin{tabular}{|c|c|c|}
\hline \multirow{2}{*}{ Seriler } & Sabit & Sabit ve Trend \\
\cline { 2 - 3 } & AIC & AIC \\
\hline$L M$ & $-2,165(0,221)[0]$ & $-3,121(0,113)[0]$ \\
\hline$L Y$ & $-1,365(0,59)[0]$ & $-2,578(0,291)[0]$ \\
\hline$L R$ & $-3,496(0,013) * *[8]$ & $-3,206(0,098) * * *[8]$ \\
\hline$\Delta L M$ & $-6,660(0,000) *[0]$ & $-6,999(0,000) *[0]$ \\
\hline$\Delta L Y$ & $-6,784(0,000) *[0]$ & $-6,904(0,000) *[0]$ \\
\hline$\Delta L R$ & - & - \\
\hline
\end{tabular}

Not: Parantez dışı değerler seriler için t-istatistik değerlerini, parantez içi değerler seriler için olasılık değerlerini, köşeli parantez içi değerler ise maksimum gecikme sayısı 10 iken seriler için gecikme uzunluğunu göstermektedir. *, **, *** serilerin sırasıyla $\% 1, \% 5$ ve $\% 10$ anlamlılık seviyelerinde durağanlığını göstermektedir.

\section{Kısıtsız Hata Düzeltme Modelleri}

İthalat fonksiyonu için kısıtsız hata düzeltme modelleri (UECM), fonksiyonların açık formlarından hareketle aşağıdaki gibi yazılmaktadır. $L M$, LY ve LR serilerinin fark değerini $\Delta Z$, düzey değerini $X$ temsil etmektedir. KIsıtsız hata düzeltme modelleri trend içermiyorsa $\Psi_{0}=0$ olarak değerlendirilmelidir:

$\Delta L M_{t}=\alpha_{0}+\Psi o t+\sum_{\mathrm{i}=1}^{\mathrm{p}} \delta_{\mathrm{i}} \Delta Z_{t-i}+\lambda X_{t}+e_{t}$

\section{Modelin Uygun Gecikme Uzunluğunun Belirlenmesi}

Çalışmada uygun gecikme uzunluğunun belirlenmesi için model 8 gecikmeye kadar AIC kriteri dikkate alınarak incelenmiştir. Bu kritere göre mutlak değerce en büyük değer, Breusch-Godfrey otokorelasyon testiyle otokorelasyon sorunu incelendikten sonra eğer otokorelasyon içermiyorsa uygun gecikme uzunluğu olarak seçilmektedir. Fakat değer otokorelasyon içeriyorsa mutlak değerce büyükten küçüğe bir sıralama olacak şekilde inceleme tekrarlanmaktadır.

Tablo 2'de yer alan trendsiz ve trendli modeller için, AIC kriterine göre mutlak değerce en büyük olan 1 . gecikme uygun gecikme uzunluğudur. Trendli modelde ise aynı kritere göre mutlak değerce en büyük olan 1. gecikme otokorelasyon içerdiğinden ilgili kritere göre 
mutlak değerce en büyük ikinci değer olan 3. gecikme, otokorelasyon içermediğinden uygun gecikme uzunluğu olarak seçilmiştir.

Tablo 2: Trendsiz ve Trendli İthalat Modeli

\begin{tabular}{|c|c|c|c|c|}
\hline \multirow{2}{*}{$\begin{array}{l}\text { Gecikme } \\
\text { Uzunluğu }\end{array}$} & \multicolumn{2}{|r|}{ Trendsiz } & \multicolumn{2}{|r|}{ Trendli } \\
\hline & AIC & B-G $\left(x^{2}\right)$ & AIC & B-G $\left(x^{2}\right)$ \\
\hline 1 & $-0,372 *$ & $0,502(0,478)$ & $-0,492$ & $3,148(0,076)^{0,1}$ \\
\hline 2 & $-0,219$ & $0,071(0,964)$ & $-0,409$ & $3,692(0,157)$ \\
\hline 3 & $-0,156$ & $2,693(0,441)$ & $-0,468^{*}$ & $0,228(0,972)$ \\
\hline 4 & $-0,148$ & $3,056(0,548)$ & $-0,314$ & $0,726(0,948)$ \\
\hline 5 & $-0,062$ & $4,592(0,467)$ & $-0,194$ & $3,913(0,561)$ \\
\hline 6 & 0.061 & $7,322(0,292)$ & $-0,013$ & $7,708(0,26)$ \\
\hline 7 & 0,17 & $11,259(0,127)$ & 0,13 & $14,665(0,04)^{0,05}$ \\
\hline 8 & $-0,235$ & $36,237(0,000)^{0,01}$ & $-0,334$ & $37,996(0,000)^{0,01}$ \\
\hline
\end{tabular}

Not: Parantez içindeki değerler olasılık değerlerini göstermektedir. *, ilgili kritere göre hem trendsiz hem de trendli model için nihai olarak belirlenen uygun gecikme uzunluğunu göstermektedir. $0,01,0,05$ ve 0,1 sırası ile $\% 1, \% 5$ ve $\% 10$ anlamlılık düzeylerinde modelin otokorelasyon sorunu içerdiğini göstermektedir.

\section{ARDL Sınır Testiyle Eş Bütünleşmenin Analizi}

$\mathrm{Bu}$ bölümde, belirlenen uygun gecikmelerden hareketle AIC kriterine göre sınır testi yardımılla eş bütünleşmenin varlığı araştırılarak uygun model belirlenmiştir.

Tablo 3: Sabit ve Trendli Modeller için Sınır Testi Sonuçları

\begin{tabular}{|c|c|c|c|c|c|}
\hline $\begin{array}{c}\text { Trend } \\
\text { Spesifikasyonu }\end{array}$ & k & Gecikme & F-Değeri & \multicolumn{2}{|c|}{$\begin{array}{c}\text { \%5 Alt-Üst } \\
\text { Sınır }\end{array}$} \\
\hline Kısıtlanmamış Sabit & 2 & 1 & 4,419 & 3,79 & 4,85 \\
\hline Kısıtlanmış Trend & 2 & 3 & $4,678^{*}$ & 3,88 & 4,61 \\
\hline
\end{tabular}

Not: *, \%5 düzeyinde $\mathrm{F}$ değerinin anlamlıı̆ını, $\mathrm{k}$ bağımsız değişken sayısını göstermektedir. $\mathrm{F}^{\prime}$ nin anlaml çıkması, bu değerin üst sınırdan büyük olması ve eş bütünleşmenin olmadığını temsil eden $\mathrm{H}_{0}$ hipotezinin reddi anlamına gelmektedir.

Trendsiz ve trendli modeller incelendiğinde uzun dönem ilişkinin var olmadığına dair boş hipotez yalnızca trendli model için reddedilmiştir. Dolayısıyla uygun model olarak trendli olan seçilerek çalışmanın geri kalanında trend içeren ithalat talep fonksiyonu incelenmiştir.

\section{Uygun Modelin Tahmini ve Sonuçları}

Bir önceki bölümde tahmin edilip uygun model olarak seçilen trendli ithalat talep fonksiyonu maksimum 3 gecikme verilerek AIC kriterine göre tahmin edilmiştir. Bu tahminden hareketle elde edilen model; ARDL $(2,0,1)$ modelinin Tablo 4'te istatistiki sonuçları verilmiştir.

Tablo 4 'teki ARDL $(2,0,1)$ ithalat talep fonksiyonunun tanısal denetim sonuçları incelendiğinde $\% 1$ düzeyinde bile modelde otokorelasyon, model kurma hatası, hata teriminin normal dağılmaması ve değişen varyans sorunlarının olmadığı ortaya çıkmaktadır. Ayrıca sabit ve LR dışındaki değişkenler istatistiki olarak anlamlıdır. 
Türkiye İçin İthalat Talep Fonksiyonu Tahmini (1970-2016)

Tablo 4: ARDL $(2,0,1)$ Modelinin Tahmini ve Tanısal Denetim Sonuçları

\begin{tabular}{|c|c|c|c|c|}
\hline Değişken & Katsayı & $\begin{array}{l}\text { Standart } \\
\text { Sapma }\end{array}$ & $\begin{array}{l}\text { T } \\
\text { İstatistiği }\end{array}$ & Olasılık Değeri \\
\hline $\operatorname{LM}(-1)$ & 0,542 & 0,137 & 3,952 & $0,0003 *$ \\
\hline $\operatorname{LM}(-2)$ & $-0,207$ & 0,122 & $-1,692$ & $0,0987 * * *$ \\
\hline $\mathrm{LY}$ & 0,58 & 0,160 & 3,612 & $0,0009 *$ \\
\hline LR & 0,163 & 0,286 & 0,571 & 0,5712 \\
\hline $\operatorname{LR}(-1)$ & $-0,582$ & 0,242 & $-2,4$ & $0,0214 * *$ \\
\hline $\mathrm{C}$ & 0,437 & 3,108 & 0,14 & 0,8889 \\
\hline @TREND & 0.023 & 0.012 & 1,826 & $0,0756 * * *$ \\
\hline \multicolumn{5}{|c|}{ 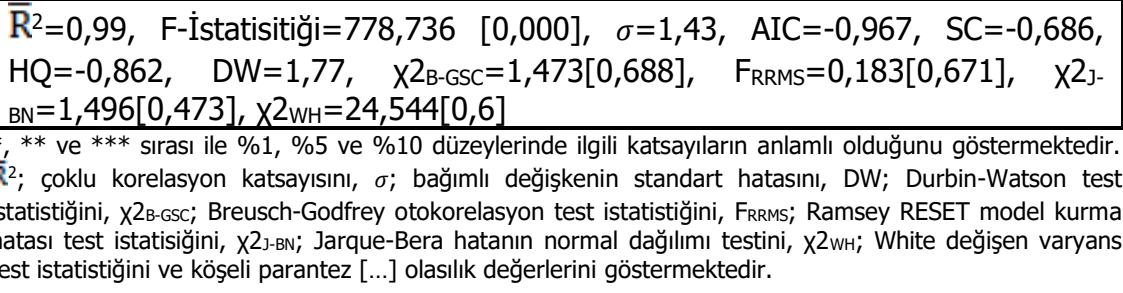 } \\
\hline
\end{tabular}

\section{Seriler Arası Kısa ve Uzun Dönem İlişkileri}

Tablo 5 incelendiğinde, -1 ile 0 arasında olması beklenen hata düzeltme teriminin $-0,625$ değerini aldığı görülmektedir. Buna göre, sistemde bir önceki dönemde meydana gelen iktisadi şokun yarattığı etkinin $\% 62,5^{\prime} \mathbf{i}$, bir sonraki dönemde düzelmektedir. Ayrıca $D(L R)$ hariç tüm katsayılar istatistiki olarak anlamlıdır.

Tablo 5: ARDL $(2,0,1)$ İthalat Talep Fonksiyonu Hata Düzeltme Modeli

\begin{tabular}{|l|l|l|l|c|}
\hline Değişken & Katsayı & $\begin{array}{l}\text { Standart } \\
\text { Sapma }\end{array}$ & T İstatistiği & Olasılık Değeri \\
\hline $\mathrm{D}(\mathrm{LM}(-1))$ & 0,195 & 0,113 & 1,726 & $0,092 * * *$ \\
\hline $\mathrm{D}(\mathrm{LY})$ & 0,657 & 0,178 & 3,678 & $0,000^{*}$ \\
\hline $\mathrm{D}(\mathrm{LR})$ & 0,069 & 0,310 & 0,223 & 0,824 \\
\hline $\mathrm{C}$ & 0,429 & 0,087 & 4,908 & $0,000^{*}$ \\
\hline $\mathrm{ECM}(-1)$ & $-0,625$ & 0,137 & $-4,559$ & $0,000^{*}$ \\
\hline
\end{tabular}

Not: $*, * *$ ve $* * *$ sırası ile $\% 1, \% 5$ ve $\% 10$ düzeylerinde ilgili katsayıların anlamlı olduğunu göstermektedir.

Tablo 6'da ithalat talep fonksiyonunun oluşturduğu değişkenler arasındaki uzun dönem katsayıları incelenmiştir. Söz konusu tablodan elde verilerle oluşturulan uzun dönem denklemi aşağıdaki gibidir:

$L M=0,872 L Y-0,629 L R+0,034 T R E N D$

Ülke geliri ile ithalat harcaması arasında beklenildiği gibi uzun dönemde pozitif, reel efektif döviz kuru ile ithalat harcaması arasında ise negatif bir ilişki söz konusudur. Fonksiyon logaritmik olduğundan önündeki katsayılar bazı esneklikleri (duyarlılıkları) vermektedir. İthalatın gelir esnekliği değeri 0,872 iken, ithalatın reel kur esnekliği $-0,629$ 'dur. Bütün değişkenler istatistiki olarak anlamlıdır. 
Can APAYDIN, Aslı Seda KURT

Tablo 6: ARDL $(2,0,1)$ İthalat Talep Fonksiyonu Uzun Dönem İlişkileri

\begin{tabular}{|l|l|l|l|l|}
\hline Değişken & Katsayı & $\begin{array}{l}\text { Standart } \\
\text { Sapma }\end{array}$ & T İstatistiği & $\begin{array}{l}\text { Olasılık } \\
\text { Değeri }\end{array}$ \\
\hline LY & 0,872 & 0,194 & 4,499 & $0,000^{*}$ \\
\hline LR & $-0,629$ & 0,216 & $-2,906$ & $0,006 *$ \\
\hline @TREND & 0,034 & 0,016 & 2,103 & $0,042^{* *}$ \\
\hline Not: *,** ve ${ }^{* * *}$ sırası ile \%1, \%5 ve \%10 düzeylerinde ilgili katsayıların anlamlı olduğunu
\end{tabular}

göstermektedir.

\section{SONUÇ}

Türkiye'nin ödemeler bilançosu incelendiğinde dış ticaret açı̆̆ının ana nedeninin ithalatın ihracattan daha fazla olmasıdır. Bu nedenle, bu çalışmada Türkiye ekonomisi açısından ithalat talep fonksiyonu üzerine odaklanılmışıı. İthalat genel olarak döviz çıkışına yol açması nedeniyle ulusal geliri/refahı olumsuz yönde etkileyen bir makro büyüklük olarak ele alınsa da günümüzde dünya ticaretinin karşılıklı bağımlııı açısından geldiği noktada, ithalatı görece çok düşük düzeyde kalan bir ekonomiye rastlamak hiç de kolay değildir. Ülkeler genelde belirli hammaddelere ve enerji kaynaklarına; belli malları ve ara malları üretecek üretim faktörlerine, bilgiye, üretim teknolojisine vb. sahip olmadıklarında ithalat yapmak zorunda kalmaktadırlar. Bir başka deyişle, bugün ülkelerin üretim ve ihracat yapmaları ithalat yapmalarına bağı hale gelmiştir. Gelişmekte olan ülkelerde üretimin ve ihracatın ithalata bağımlılığı oldukça yüksektir. Ayrıca ülkeler arasındaki ticaret kanalıyla bilgi ve teknoloji transferini sağladığı gerekçesiyle de zorunlu bir akım olarak değerlendirilmektedir.

Çalışmadaki kırk yedi yıllık periyotta gelir etkisi incelendiğinde, ülke gelirinde meydana gelen $\% 1^{\prime}$ lik bir artışın ithalat talebini $\% 0,872$ artırdığı görülmektedir. Bir başka ifadeyle, ithalatın gelire duyarlıı̆ı 0 ile 1 arasında ve inelastiktir. Gelir esnekliğinin 0'dan büyük olması Türkiye'nin daha çok, teoride normal olarak tanımlanan malları ithal ettiğini göstermektedir. Fiyat etkisi açısından incelendiğinde ise reel efektif döviz kurunda meydana gelen \%1'lik artışın ithalat talebini \%0,629 azalttığı görülmektedir. İthalat talebinin kura karşı duyarlılı̆ının beklenildiği gibi 0 ile -1 arasında olması durumu, göreli fiyatların artmasının ithalat talebini düşürme yönünde etkili olduğu anlamına gelmektedir.

Türkiye gibi gelişmekte olan bir ülkede ulusal gelir arttıkça ithalatın neredeyse bu gelir artışı kadar artması kaçınılmazdır. Bu kanaldan ithalatın azalmasını beklemek ve/veya bunun için ulusal geliri düşürmek önerilebilir seçenekler değildir. Çalışmada mal bazında analizler yapılmamış olsa da bilindiği gibi Türkiye önemli ölçüde enerji ithal 
ettiğinden yurt içi üretimin ithalata bağımlılığı yüksektir. Bu bilgiler göz önüne alındığında Türkiye için dış ticaret açığının ana kaynağı olan ithalatı kısa dönemde mutlak olarak azaltmak mümkün olmadığından ihracatın artırıması yoluyla dış ticaret açığının azaltılması daha rasyonel bir politika olacaktır. Bunun için katma değeri yüksek malların üretilip ihraç edilmesi özetle uzun vadeli yatırımların artıııması gerekmektedir. Ayrıca dünya ticaretinin güncel seyrine istinaden gelişmiş ülkeler gibi ithalata vergi koymak, üretimde ara malları ve enerji bağımlılığı sebebiyle üretim maliyetlerini artıracaktır. Ayrıca Türkiye'nin de üyesi olduğu Dünya Ticaret Örgütü gibi uluslararası kuruluşların ve entegrasyon anlaşmalarının (Türkiye ile Avrupa Birliği arasındaki Gümrük Birliği Anlaşması gibi) getirdiği yükümlülükler, ithalatın dış ticaret politikası araçları kullanılarak kontrol altında tutulmasını ve/veya azaltımasını engellemektedir. Dolayısıyla ithalat vergisi uygulaması yerine üretim ölçeğini üretim teknolojisindeki gelişmeler yardımıyla artırmaya çalışmak daha rasyonel olacaktır. Bu nedenle üretimde yapısal dönüşümün bir an önce gerçekleştirilmesi, dünya piyasalarındaki gelişmelerin ve özellikle Endüstri 4.0 sürecinin yakından izlenmesi hayati önem taşımaktadır. Türkiye de artık diğer gelişmiş ülkeler gibi sadece fiyat rekabeti içinde yer almak yerine kalite, yenilik, satış sonrası hizmetler gibi alanlarda rekabet avantajları elde etmenin yolunu aramalıdır. Bu amaçla, Türkiye ile hemen hemen aynı gelişmişlik düzeyinde iken daha sonradan dünya üretimi ve ticareti açısından son derece kritik noktalara gelmiş Güney Kore gibi ülke deneyimlerinin incelenmesi önerilebilir. Türkiye'nin kendi potansiyeline ve piyasa ihtiyaçlarına uygun bir üretim yapısını hızı bir şekilde oluşturması gerekmektedir. Yenilenebilir ve yerli enerji kaynaklarının kullanımının yaygınlaştırıması, Ar-Ge harcamalarına ayrılan payın artırıması, girişimciliği ve yeniliği özendiren bir eğitim ve üretim kültürü oluşturulması, yerli hammadde ve ara mallarına dayalı sanayinin teşvik edilmesi, sanayi ve ticaret politikalarının uyumlaştırıması ve stratejik dış ticaret politikaları ile dış ticaret kazançlarının Türkiye'ye çekilmesinin sağlanması yerinde olacaktır.

\section{KAYNAKÇA}

Altıntaş, H. ve Türker O. (2014). The Dynamics of Export and Import Functions in Turkey: Cointegration and Multivariate Granger Causation Analysis. International Journal of Asian Social Science, $4(5), 676-689$. 


\section{Can APAYDIN, Aslı Seda KURT}

Aydın, F., Çıplak, U. ve Yücel, M.E. (2004). Export Supply and Import Demand Models for the Turkish Economy. CBRT, Research and Monetary Policy Department, Working Papers, 04 (9), 1-29.

Bahmani-Oskooee, M. (1998). Cointegration Approach to Estimate the Long-run Trade Elasticities in LDCs. International Economic Journal, 12(9), 89-96.

Bahmani-Oskooee, M. ve Niroomand, F. (1998). Long-run Price Elasticities and the Marshall-Lerner Condition Revisited. Economics Letters, 61(1), 101-109.

Bahmani-Oskooee, M. ve Kara, O. (2005). O. Income and Price Elasticities of Trade: Some New Estimates. The International Trade Journal, 19(2), 165-178.

Bayraktutan, Y. ve Bıdırdı, H. (2010). Türkiye'de İthalatın Temel Belirleyicileri. Ege Akademik Bakış, 10(1), 351-369.

Bayramoğlu A.T., ve Şükrüoğlu, D. (2016). Non-Energy Import Demand Function in Turkey: New Evidence. Asian Economic and Financial Review, 6(12), 750-761.

Constant, S. ve Yue, Y. (2010). An Econometric Estimation of Import Demand Function for Cote D'Ivoire. International Journal of Business and Management, 5(2), 77-84.

Dickey, D. ve Fuller, W.A. (1979). Distribution of the Estimators for Autoregressive Time Series with a Unit Root. Journal of the American Statistical Association, 74(366), 427-431.

Dickey, D. ve Fuller, W.A. (1981). Likelihood Ratio Statistics for Autoregressive Unit Root. Econometrica, 49(4), 1981, 813-836.

Dutta, D. ve Ahmed, N. (2004). An aggregate Import Demand Function for India: A Cointegration Analysis. Applied Economics Letters, 11(10), 607-613.

Englama, A., Oputa, N.C., Sanni, K., Yakub, M.U., Adesenya, O., ve Sani, Z. (2013). An Aggregate Import Demand Function for Nigeria: An Auto-Regressive Distributed Lag (ARDL) Approach. Economic and Financial Review, 51(3), 1-18.

Engle, R.F. ve Granger, C.W. (1987). Co-integration and error correction representation, estimation and testing. Econometrica, 55(2), 251276.

Fosu, O.E. ve Magnus, F.J. (2008). Aggregate Import Demand and Expenditure Components in Ghana. Journal of Social Sciences, 4(1), 1-6. 
Fullerton, T.M.Jr., ve Sprinkle, R.L. (2005). An Error Correction Analysis of U.S.-Mexico Trade Flows. International Trade Journal, 19(2), 179-192.

Gözgör, G. (2014). Aggregated and disaggregated import demand in China: An empirical study. Economic Modelling, 43, 1-8.

Gül, E. ve Ekinci, A. (2006). Türkiye'de Reel Döviz Kuru ile İhracat ve İthalat Arasındaki Nedensellik İlişkisi: 1990-2006. Dumlupınar Üniversitesi Sosyal Bilimler Dergisi, 16, 165-190.

Hye, Q.M.A. ve Mashkoor, M. (2010). Import Demand for Bangladesh: A rolling window analysis. African Journal of Busines Management, 4(10), 2150-2156.

Johansen, S. (1988). Statistical Analysis of Cointegration Vectors. Journal of Economic Dynamics and Control, 12(2-3), 231-254.

Johansen, S. ve Juselius, K. (1990), Maximum Likelihood Estimation and Inference on Cointegration - with Application to the Demand for Money. Oxford Bulletin of Economics and Statistics, 52(2), 169210.

Kalyoncu, H. (2006). An Aggregate Import Demand Function for Turkey, the Indian Journal of Economics, 86 (343), 1-12.

Kotan, Z. ve Saygllı, M. (1999). Estimating an Import Function for Turkey. CBRT, Research Department, Discussion Paper, 9909, 128.

Kutlar, A. ve Şimşek, M. (2003), Türkiye'de İthalat Talebi'nin Koentegrasyon Analizi 1987(I)-2000(IV). Dokuz Eylül Üniversitesi İktisadi ve İdari Bilimler Fakültesi Dergisi, 18(2), 65-82.

Mugableh, M.I. (2017). Estimating Elasticity Function of Jordanian Aggregate Import Demand. Applied Economics and Finance, 4(2), 33-37.

Narayan, S. ve Narayan, P.K. (2003). Import Demand Elasticities for Mauritius and South Africa: Evidence from Two Recent Cointegration Techniques. Monash University Department of Economics Discussion Papers, 09 (3), 1-35.

Onwuka, O.K. ve Zoral, K.Y. (2009). Foreign Direct Investment and Imports Growth in Turkey, Journal of Yasar University, Cilt: 4, Sayı: 15, 2357-2380.

Pesaran, H., Shin, Y. ve Smith, R.J. (2001). Bound Testing Approaches to the Analysis of Long Run Relationship. Journal of Applied Econometrics, 16(3), 289-326. 


\section{Can APAYDIN, Aslı Seda KURT}

Rehman, H.U. (2007). An Econometric Estimation of Traditional Import Demand Function for Pakistan. Pakistan Economic and Social Review, 45(2), 245-256.

Said, S.E. ve Dickey, D. (1984). Testing for Unit Roots in Autoregressive Moving Average Models of Unknown Order. Biometrika, 71(3), 599-607.

Shareef, R. ve Tran, V. (2007). An Aggregate Import Demand Function for Australia: A Cointegration Approach. School of Accounting, Finance and Economics \& FEMARC Working Paper Series, 1-34.

Togan, S. ve Berument, H. (2007). The Turkish Current Account, Real Exchange Rate and Sustainability: A Methodological Framework, The Journal of International Trade and Diplomacy, $1(1), 155-192$.

Utkulu, U. ve Seymen, D. (2004). Trade and Competitiveness between Turkey and the EU: Time Series Evidence. Turkish Economic Association, Discussion Paper, 4 (8), 1-46.

Vergil, H. ve Erdoğan, S. (2009). Döviz kuru-Ticaret Dengesi İlişkisi: Türkiye Örneği. Zonguldak Karaelmas Üniversitesi Sosyal Bilimler Dergisi, 5(9), 35-57.

Wijeweera, A., Bur, M. ve Dollery, B. (2008). Bilateral Import Demand Elasticities the Case of Bangladesh. International Research Journal of Finance and Economics, 19, 114-125.

Yamak, R. ve Korkmaz, A. (2005). Reel Döviz Kuru-Ticaret Dengesi İlişkisi: Kritik Elastikiyetler (Marshall-Lerner) Şartı. İstanbul Üniversitesi İktisat Fakültesi Ekonometri ve İstatistik Dergisi, 2, 1129.

Yavuz, N.Ç. ve Güriş, B. (2006). An Aggregate Import Demand Function for Turkey: The Bounds Testing Approach, ODTÜ Gelişim Dergisi, Cilt: 33, Sayı: 2, 311-325. 